\title{
Design of the UX Laboratory for the Department of Communications
}

\author{
Juraj Fabus', Viktoria Fabusova² \\ ${ }^{1}$ Department of Communications, University of Zilina, Slovakia, ${ }^{2}$ Department of \\ Quantitative Methods and Economic Informatics Economics, University of Zilina, \\ Slovakia.
}

\begin{abstract}
The aim of this paper is to design a laboratory suitable for UX (User eXperience) testing. The theoretical part identifies basic problems when designing products from a customer perspective. The analytical part consists of the research of the existing UX laboratories in the world as well as the possibilities of using such a laboratory in the activities of the Department of Communications or the whole faculty. In the case of the Department of Communication, which is part of the Žilina University in Žilina, the possibilities of using UX laboratories are different, for example: improving the learning process, providing modern and interesting education, helping to create student presentations, websites and its design, work on research and scientific projects, training of marketing methods. We are discussing these options in detail in this paper. The UX Laboratory can also be used to support scientific and research tasks. In the design part, a laboratory is designed both technically and economically in the environment of the Department of Communications.
\end{abstract}

Keywords: User eXperience, laboratory design, modern education. 


\section{Introduction}

Today's world of modern technology and its constant improvement are forcing people to think and work to exploit every opportunity to achieve the best results. Measuring User eXperience (UX) is everywhere around us. The key benefits of UX can be found mainly in marketing, product design, web design and tourism, which are subjects taught at our department in the E-commerce and management study program. The aim of this paper is to analyse and design a laboratory suitable for UX testing.

It is not so easy to make a quality product for each user. The buyer has several of his own requirements and focuses mainly on the price, design and prestige of the product at the shop. At home he looks mainly at functionality and usability (Fendrych, 2010). Jeff Johnson sees design as a creative process whose boundaries are often very narrow. Our decision about what we want to create is based on the principles of design. But in the next case, we are greatly influenced by emotions during disign activities (Mauser, 2012).

\section{UX tools}

There are many tools and methods for exploring user experience. We know a wide range of research methods which we have at disposal, from try and know methodsm which are based on laboratory bases, to methods based on online bases (Figure 1).

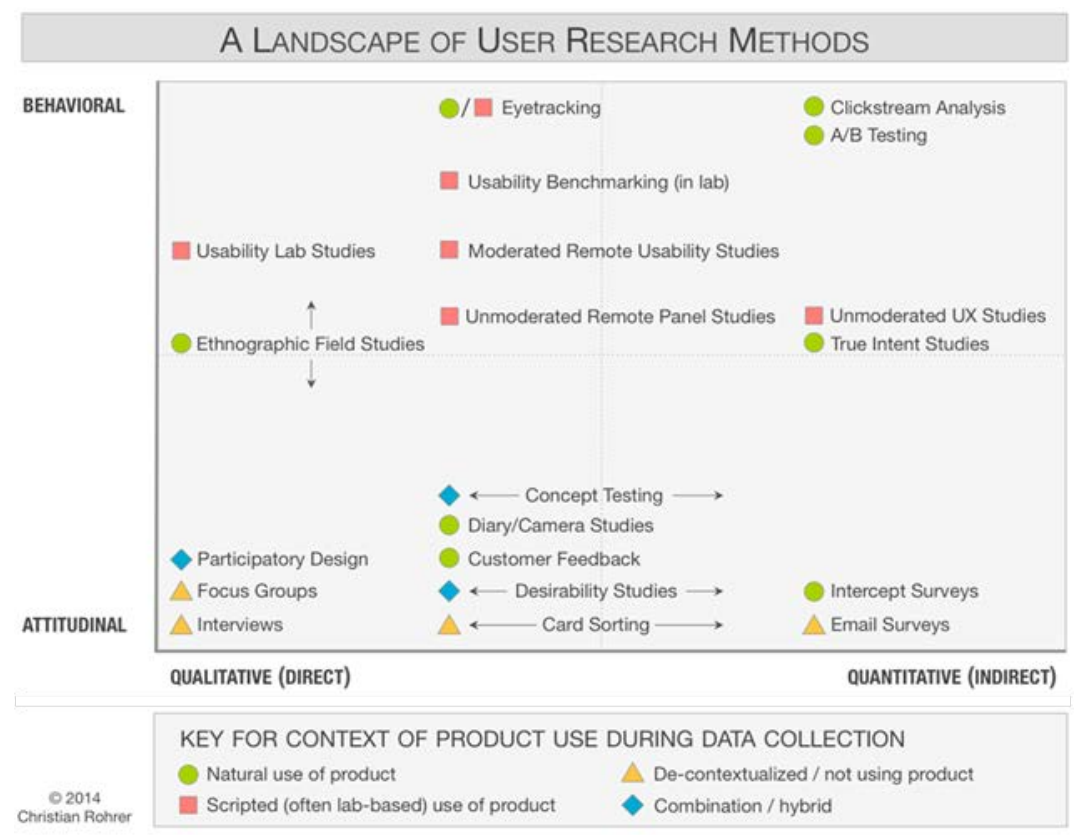

Figure 1.User research methods. 
Many organizations still believe that usability testing is a luxury that requires costly laboratories and is time consuming. In fact, usability testing can be as fast as it is relatively inexpensive. Precious prototypes are not needed - papers research can also produce valuable results. Necessary participants need not to be many - even 5 users may be enough to test specific tasks. Jakob Nielsen says, that under normal circumstances, testing on five users is enough. He claims that by adding more and more users, you will learn less and less (Nielsen, 2000).

\section{UX laboratories}

Researchers focus on behaviour, attitudes, motivations, and emotions when using a particular product, system, or service in the UX Laboratory. Thus, UX includes the ability to measure and record user behaviour (such as efficiency, economy and learnability) and subjective experience (such as affective, meaningful, and value aspects) from humancomputer interaction. Three types of rooms are usually used in UX laboratories (Capkova et al., 2013) - Test room, Observation room and Evaluation room.

As a part of research, we have been investigating laboratories in the world. Information about UX laboratories was not easy to get. Therefore, we focused our research on the UX Laboratories in Europe and we were able to get the detailed technical specifications of two UX laboratories, one from Germany and another one from Netherlands.

When working with UX, the following devices are used:

- Trackers - Pupil Labs Headset, Tobi EyeX / SteelSeries Sentry, The Eye Tribe Tracker, TOBII X2-30,

- $\quad$ EEG devices - MindWave (NeuroSky), Epoc (Emotive), BrainAmp Standard (Brainproducts),

- Additional Equipment of UX Laboratory - Pulse Meter, Pressure Gauge, ECG / ECG, EMG.

\subsection{Possibilities of using UX laboratories}

In the case of the Department of Communications, which is part of the Žilina University in Žilina, the possibilities of using UX laboratories are diverse, for example:

\section{a. Possibility of testing students' response to study materials}

Study materials could be tested to improve the quality of education at the Department of Communications (Binda, Stofkova Repkova 2017). In the case of testing students' response to study materials, it is possible to test teaching materials available to teachers in the e-learning education system. Teachers would then get the information they need to analyze student needs and their responses. They 
would find out whether the students' study materials were interesting, understood, or attracted by their design. T. Bata claimed, "Our customer, our lord," which is also true in this case.

b. Possibility of testing student work, presentations of thesis, and representative materials of the Department of Communications

Testing designed for students to prepare different school projects. Students should be able to test audience responses to presentations intended for defence of diploma and bachelor's theses. They could create interesting and engaging presentations to defend their final work.

\section{c. Possibility to test the design and functionality of websites and e-commerce}

Students of the Department of Communications are studying subjects such as web design, web development, and more. Upon these learning subjects they are taught to create multimedia websites. The UX Laboratory would allow students to test their school projects web sites and e-commerce. This would improve the website's performance features, and user-friendly design. They would gain the knowledge needed to create user-oriented web sites. From these experiences with creating a user-oriented website, they could benefit from their work after graduating.

d. Possibility to use the UX laboratory in the teaching of various subjects. Usage in the teaching of modern marketing methods and management

The potential of the UX laboratory could be used to teach different subjects. Such a laboratory would provide teachers with new opportunities and approaches to their teaching, enabling students to be involved in the learning process or improving collaboration between teachers and their students (Madlenak et al., 2017). The benefits of the UX Laboratory would also be significant when studying new, modern marketing methods. Students would acquire knowledge based on the support of modern technologies.

e. Possibility of using the UX laboratory for scientific purposes and for cooperation with external companies

The added value of the UX Laboratory at the Department of Communication, would be significant in performing the scientific work of the Department. The UX laboratory could be used in research and scientific projects carried out by the department, or research projects implemented in cooperation with other organizations and universities. The number of UX laboratories in Slovakia is still lagging behind the more advanced countries. It is therefore possible to take advantage of the state of the market and to build a UX laboratory for commercial use to test web sites, e-commerce and products of these companies. 


\subsection{Design of the UX laboratory for the Department of Communications}

The first option that was considered, was the expansion of an existing UX lab. This option has to be based on existing technical features and technologies. This may be problematic if we want to use different technologies. The application of different technologies from different companies can cause incompatibilities. We did not choose the variant of the modernization an existing laboratory or a test room because the existing device is outdated. Investing in modernization would be so inappropriate (Tothova, 2018) therefore a better solution would be to design own UX laboratory from the beginning.

Based on the analysis of existing laboratories, we have decided to solve the UX laboratory project by developing three options at a different expense. In the following sections of the paper, three variants of the UX lab design will be described at different cost. The first design of the laboratory will be based on the idea of lowering costs to a minimum. It will be a variant where only simple and inexpensive hardware devices will be used without the use of an eye tracker. In case of the second option, we will add the use of an eye tracker at lower price, than in the last third variant, which includes the use of a better quality eye tracking technology as well as biometric devices.

Detailed reports, analyzes of equipment and software as well as evaluation of analyzes can be delivered on request or presented at the conference. Because of the extent of the paper, we do not provide detailed hardware equipment for individual variants.

\section{a. Variant One - A simple and inexpensive UX lab}

The first variant of a simple and inexpensive UX lab is based on the fact that the cost of building the lab will be low. It will be designed for more interesting learning and testing among students and developing marketing methods and customer knowledge. We set the budget for securing laboratory components to 2500 euros. The software is required for proper functionality and communication between all devices. The software selection is adapted to keep costs at the lowest possible level. However, it is necessary to ensure the maximum functionality of all devices. We chose Zonescreen, Fraps, IOGraphica and WhatPulse. The lab is suitable for student testing, simple research tasks, tracking responses to performing tasks, and an interesting way to teach. The cost of the software equals zero. All applications required for laboratory activity are available free of charge.

\section{b. Variant Two - Laboratory with eye tracking technology}

After analyzing the market for available devices that support eye tracking technology, we've decided to increase the budget to an amount that will be enough to secure this technology. We have requested price offers for study and educational purposes. The decisive criterion was the price. For an investment of EUR 5000, it 
is possible to provide a laboratory at a higher technical level of research. The software to ensure the laboratory is in the second variant an application pack from the Gazepoint company. The second variant - a lab with eye tracking technology allows us to better record the responses of the test person. To obtain more accurate data, the use of eye tracking technology is crucial. For the eye tracker from Gazepoint company, we decided upon the evaluation of the technical specifications and a comparation with the concurents. The concurents provided products with a greater degree of accuracy and functionality, but did not meet the requirements for building a laboratory even with an increased budget of 6000 euros.

\section{c. Variant three - Laboratory with eye tracking technology and biometric systems}

UX laboratory based on SMI technology is available at university. Based on the price analysis of available products and the TOBII price consulting, we have decided for a budget of 20,000 euros. The price of TOBII devices is lower than the price of competing devices used in SMI's current university lab. Consultation with experts has confirmed that TOBII technology will be suitable for university use. Design of the variant three calculates with the use of biometric systems to track the body response during the testing. Brain monitoring devices (EEG), an EMG muscle tracking device, and a device monitoring ECG cardiac activity will be used. Based on the information obtained from all of these technologies in a real time, it will be possible to ensure high accuracy of measurement and the data obtained by measuring will be more accurate. It is therefore possible to get the exact data which are needed for research and scientific activity. The software equipment in this case consists of Tobii Pro Lab and EMOTIV Pure EEG. The third variant - a laboratory of the highest technological level of research from all provides improved eye tracking technology along with the use of biometric data. The accuracy of the data obtained will thus reach the highest level of all three variants. Building a TOBII-based laboratory could have a positive impact on the research processes of the Department of Communications. It would be possible to compare the results between the TOBII laboratory and the SMI-based laboratory.

\section{Conclusion}

The paper can be used as an overview of possible solutions for building a UX laboratory for different conditions of use, and at different costs. It can serve as a practical guide for the implementation of a particular UX laboratory. There is not paid much attention to user testing in Slovakia. We have obtained some technical specifications of UX laboratories in 
Europe, which was difficult to receive, because of their unwillingness to cooperate and provide more detailed technical specifications. Information and technical specifications for components have been obtained from the producer of the individual equipment. The next planned step of the research is to examine the possibilities of UX laboratory implementation not only at universities in Slovakia, but also in the EU, or worldwide. To do this, it will be necessary to identify differences in the academic environment between countries.

\section{Acknowledgements}

The article was created on the basis of grant support of VEGA 1/0725/17 Research of startup company lifecycle as the basis of the start-up business model of a network enterprise and by Ministry of Education, Science, Research and Sport of the Slovak republic.

\section{References}

Binda, J., Stofkova Repkova, K., "Organizational and financial aspects of blended learning implementation at the university as teaching supporting solution”, Conference: 10th Annual International Conference of Education, Research and Innovation (ICERI), Location: Seville, SPAIN, Date: NOV 16-18, (ICERI2017), Book Series: ICERI Proceedings, Pages: 2250-2256, Published: 2017.

Capková, E., Juchová, Z., Tornáryová, I., “Laboratórium testovania použitel’nosti v projekte Pamät' Slovenska In Ikaros”, online: <https://ikaros.cz/laboratorium-testovaniapouzitelnosti-v-projekte-pamaet-slovenska>, ISSN 1212-5075, 2013.

Fendrych, A., “User Experience - poznejte své uživatele”, In Lupa.cz: server o českém Internetu, online: <http://www.lupa.cz/clanky/user-experience-poznejte-sve-uzivatele/>, ISSN 1213-0702, 2010.

Madlenak, R., Madlenakova, L., Rudawska, A., "Viral marketing as part of effective university marketing strategy", Conference: 11th International Conference on Technology, Education and Development (INTED), Location: Valencia, SPAIN, Date: MAR 06-08, 2017, INTED2017: Book Series: INTED Proceedings, Pages: 5629-5634, Published: 2017.

Mauser, K. S., "Designing with the mind in mind: An interview with Jeff Johnson”, online: $<$ http://www.uxmatters.com/mt/archives/2012/02/designing-with-the-mind-in-mind-aninterview-with-jeff-johnson.php>, 2012.

Nielsen, J., "Why You Only Need to Test with 5 Users In Nielsen Norman Group”, online: $<$ https://www.nngroup.com/articles/why-you-only-need-to-test-with-5-users/>, ISSN 0737-8939, 2000.

Tothova, D., "Websites of Slovak Universities”, International Scientific Days 2018, DOI: 10.15414/isd2018, Pages:10-13, 2018. 